\title{
VARIASI KADAR TINER DAN TEMPERATUR PENGERINGAN TERHADAP KUALITAS HASIL PENGECATAN BODI KENDARAAN BERBAHAN ABS
}

\author{
Variation Of Tinner Level And Drying Temperature On Quality of ABS Vehicle Bodies Painting
}

\author{
Dicky Adi Tyagita ${ }^{1)}$, Aditya Wahyu Pratama2), Darno Bagus Aprianto ${ }^{3)}$ \\ ${ }^{1,2,3)}$ Program Studi Mesin Otomotif, Jurusan Teknik, Politeknik Negeri Jember \\ Email: ${ }^{1)}$ dickyadi@polije.ac.id, ${ }^{2}$ aditya_wa@polije.ac.id, ${ }^{3)}$ darnoaprianto@gmail.com
}

\begin{abstract}
ABSTRAK
Pengecatan adalah suatu proses aplikasi cat dalam bentuk cair pada sebuah obyek, untuk membuat lapisan tipis yang kemudian membentuk lapisan keras atau lapisan cat. Faktor-faktor yang mempengaruhi kualitas pengecatan adalah bahan yang digunakan, temperatur saat pengecatan, serta keahlian dalam mengecat. Penelitian ini meneliti tentang daya lekat dan daya kilap cat dengan variasi temperatur pengecatan dan viskositas cat yang diterapkan pada bodi kendaraan berbahan ABS. Penelitian daya kilap cat dilakukan di PT Mataram Paint Surabaya, sedangkan pengujian daya lekat cat dan pembuatan spesimen dilakukan di laboratorium otomotif Politeknik Negeri Jember. Hasil pengujian nilai daya kilap terendah sebesar $67,48 \mathrm{GU}$ terdapat pada temperatur $32{ }^{\circ} \mathrm{C}$ dengan perbandingan antara volume cat dan tiner 1:1, sedangkan nilai daya kilap tertinggi sebesar 89,35 GU terdapat pada suhu $70{ }^{\circ} \mathrm{C}$ dengan perbandingan 1:1,3 antara volume cat dan tiner. Hasil pengujian daya lekat cat rata-rata semua komponen memiliki daya lekat yang baik dan termasuk dalam kelas 5B. Semakin tinggi viskositas cat menyebabkan kadar nitroselulosa dalam cat semakin tinggi sehingga menyebabkan nilai daya kilap semakin rendah namun daya tahan cat terhadap goresan meningkat. Sebaliknya viskositas cat semakin rendah menyebabkan kadar nitroselulosa dalam cat semakin rendah menyebabkan nilai daya kilap semakin tinggi, namun daya tahan cat terhadap goresan menurun.
\end{abstract}

Kata Kunci: viskositas, temperatur, daya kilap, daya lekat, nitroselulosa

\begin{abstract}
Painting is a process of application of paint in liquid form on an object, to make a thin layer which then forms a hard layer or a layer of paint. Factors affecting the quality of painting are the material used, the temperature at the time of painting, and painting skills. This research studies about adhesive level and paint gloss level with painting temperature variety and paint viscosity applied in vehicle body made from ABS. The paint gloss meassure in PT Mataram Paint Surabaya, while the paint adhesion testing and specimen making were carried out in the Automotive laboratory State Polytechnic of Jember. The lowest paint gloss test result is $67,48 \mathrm{GU}$ existed in $32{ }^{\circ} \mathrm{C}$ with comparison between the paint volume and thinner 1:1,but the highest paint gloss Power is 89,35 $G U$ existed in $70{ }^{\circ} \mathrm{C}$ with comparison between the paint volume and thinner 1:1,3. The paint adhesive test result shows that most of the component has good adhesive and included to $5 B$ class. The higher viscosity make the paint gloss lower but the paint scratcth resistance higher. But the low paint viscosity decrease the nitroselulosa in paint and it makes the paint gloss higher, but the paint scratch resistance is lower.
\end{abstract}

Keywords: viscosity, temperature, gloss level, adhesive level, nitrosellulosa

\section{PENDAHULUAN}

Banyak sekali indikator yang dapat dijadikan acuan untuk menilai kualitas suatu kendaraan. Salah satu dari indikator tersebut adalah kualitas cat pada bodi kendaraan. Bodi kendaraan merupakan bagian terluar yang memberi aspek keindahan guna menjadi daya tarik bagi konsumen. Karena menjadi bagian terluar dari kendaraan, maka bodi kendaraan rentan terhadap bahaya dari luar misalnya cat yang lecet, bodi yang penyok serta warna cat yang mulai mengkusam.
Kondisi lalu lintas yang semakin padat serta akses jalan yang kurang memadai akan meningkatkan potensi terjadinya kecelakaan lalu lintas atau benturan antar kendaraan yang bisa menyebabkan kerusakan bodi yang menyebabkan nilai dari keindahan dan estetika dari mobil tersebut menurun. Jika hal tersebut terjadi, perlu adanya penanganan guna memperbaiki bodi kendaraan yang sudah rusak. Untuk itu perlu dilakukan pengecatan agar bodi kendaraan bisa 
kembali seperti semula saat kendaraan itu baru selesai diproduksi oleh pabrikan asal.

Pengecatan adalah suatu proses aplikasi cat dalam bentuk cair pada sebuah obyek, untuk membuat lapisan tipis yang kemudian membentuk lapisan keras atau lapisan cat (PT Toyota Astra Motor, 2011). Faktor-faktor yang mempengaruhi kualitas pengecatan adalah bahan yang digunakan, viskositas cat, temperatur pengecatan, serta keahlian dalam mengaplikasikan cat.

Dian Arif Irawan dan Diah Wulandari (2016) dalam penelitian "Pengaruh Jarak Penyemprotan Spray Gun dan Perbandingan Campuran Cat Dengan Thinner Terhadap Kualitas Hasil Pengecatan" menyatakan bahwa jarak penyemprotan spray gun $18 \mathrm{~cm}$ dengan perbandingan campuran 1:1,4 menghasilkan tingkat kekilapan terbaik GU tertinggi 96,22 untuk penggunaan cat dengan merk Nippe 2000. Jarak penyemprotan spray gun $18 \mathrm{~cm}$ dengan perbandingan campuran 1:1,5 menghasilkan tingkat kekilapan terbaik untuk penggunaan cat dengan merk danagloss dengan hasil GU tertinggi 95,57.

Fachrudin Indra Permana dan Syaiful Anwar (2014) dalam penelitian "Pengaruh Kualitas Thinner Pada Campuran Cat Terhadap Hasil Pengecatan" menyatakan bahwa Pada cat dengan merk nippe 2000 didapatkan bahwa dengan menggunakan perbandingan campuran 1:1,4 yang dicampur menggunakan tiner $\mathrm{A}$ special dengan nilai kekilapan terbaik di antara tiner yang lain dan campuran yang lain yaitu 89,1 GU. Pada cat dengan merk danagloss didapatkan bahwa dengan menggunakan perbandingan 1:1,5 yang di campur menggunakan tiner cemerlang menghasilkan tingkat kekilapan yang bagus dan tidak mengalami kecacatan karena tingkat kekentalan yang kurang baik yaitu efek runs atau meleleh karena terlalu encer ataupun efek seperti kulit jeruk karena terlalu kental, dengan nilai kekilapan 86,4 GU.

Berdasarkan penelitian di atas belum dilakukan penelitian mengenai bagaimana pengaruh viskositas cat dan temperarur pengeringan terhadap kualitas hasil pengecatan. Tujuan dari penelitian ini adalah mengukur daya lekat dan daya kilap cat dengan variasi temperatur pengecatan dan viskositas cat akibat tingkat penambahan tiner sebagai campuran cat yang diterapkan pada bodi kendaraan berbahan ABS. Harapan dari penelitian ini adalah mendapatkan nilai daya rekat dan daya kilap pada cat dengan variasi viskositas dan temperatur pengeringan yang dapat digunakan sebagai acuan untuk proses pengecatan secara umum.

\section{METODE}

Penelitian ini dilakukan secara eksperimental, dan dilaksanakan di PT Mataram Paint Surabaya untuk pengambilan data daya kilap cat menggunakan glossmeter Khasib dan Wulandari (2017), sedangkan pengujian daya lekat cat sesuai standart ISO 2409:2007 dan pembuatan spesimen dilakukan di laboratorium otomotif Politeknik Negeri Jember. Spesimen yang digunakan dalam penelitian ini adalah dari bahan ABS yang dipotong dengan ukuran $10 \mathrm{~cm}$ $\mathrm{x} 10 \mathrm{~cm}$ yang telah dipersipakan permukaanmya dengan cara di ratakan permukaannya dengan amplas, sehingga siap untuk dilakukan proses pengecatan. Berikut adalah table grid amplas dan penggunaannya.

Tabel 1. Grit pada amplas dan penggunaannya

\begin{tabular}{llll}
\hline No & Nomor Grit & Tipe Pekerjaan & \\
\hline 1 & $60-80$ & Mengupas Cat & \\
2 & $80-180$ & Feather edging & \\
3 & $180-320$ & Mengamplas Polyester Putty & \\
4 & $320-1000$ & Mengamplas Surfacer & \\
5 & $1000-2000$ & $\begin{array}{l}\text { Mengamplas cepat setelah Top } \\
\text { Coat }\end{array}$ & \\
& & &
\end{tabular}

Sumber: Gunadi, 2008

Sebelum melakukan pengecatan pada spesimen berbahan ABS langkah pertama adalah menyemprotkan PP Primer yang berfungsi agar cat merekat dengan kuat pada spesimen. Viskositas cat setelah dicampur dengan tiner diukur terlebih dahulu dengan Viscometer Oswaldt (Tirta, 2019). Pengeringan cat menggunakan oven $\left(32{ }^{\circ} \mathrm{C}, 45^{\circ} \mathrm{C}, 70\right.$ $\left.{ }^{\circ} \mathrm{C}\right)$ dan non oven. PP Primer, epoxi dan surfacer menggunakan pengeringan non oven. Top coat dan clear menggunakan pengeringan cat dengan variasi temperatur dan variasi viskositas cat. Pengeringan dalam oven dilakukan selama satu jam. Proses penelitian dijelaskan secara sederhana oleh diagram alir penelitian sebagai berikut. 


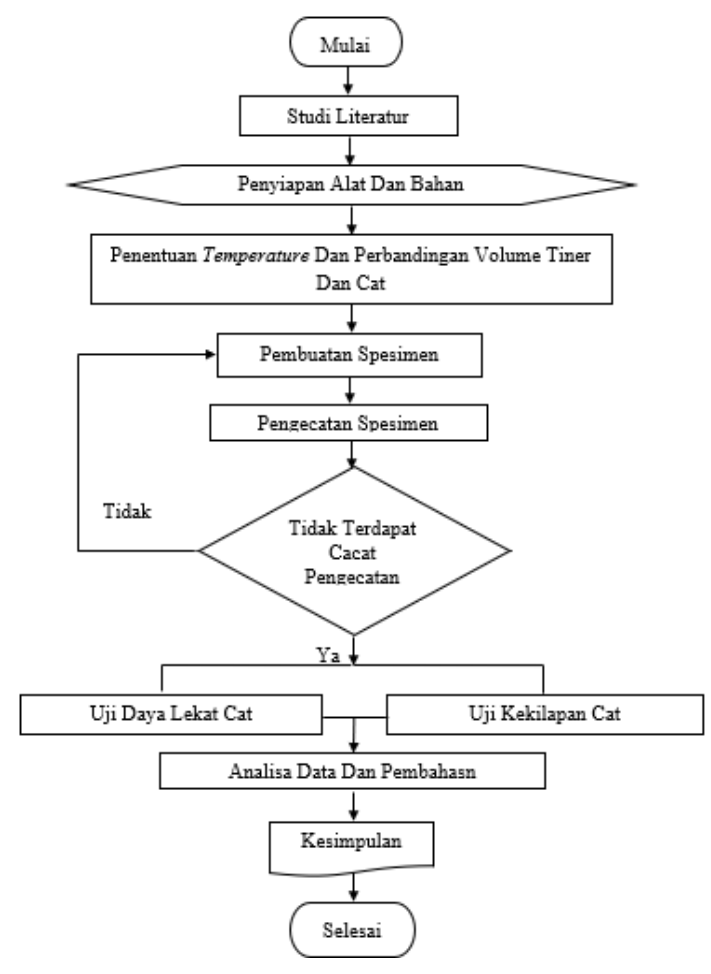

Gambar 1. Diagram alir penelitian

\section{HASIL DAN PEMBAHASAN}

\section{Hasil Pengujian Viskositas Cat}

Pengujian viskositas cat menggunakan alat viskometer oswalt. Pengujian ini bertujuan untuk mengetahui tingkat kekentalan cat dan pengaruhnya terhadap hasil pengecatan. Hasil pengujian nilai viskositas dapat dilihat pada Tabel 2.

Tabel 2. Nilai Viskositas

\begin{tabular}{lll}
\hline No & Nama & Viskositas $\left(\mathrm{Ns} / \mathrm{m}^{2}\right)$ \\
\hline 1 & PP Primer & $10,592 \times 10^{-4}$ \\
2 & Epoxi & $31,057 \times 10^{-4}$ \\
3 & Surfacer & $23,901 \times 10^{-4}$ \\
4 & Clear $1: 1$ & $15,298 \times 10^{-4}$ \\
5 & Clear $1: 1,1$ & $13,921 \times 10^{-4}$ \\
6 & Clear $1: 1,2$ & $11,012 \times 10^{-4}$ \\
7 & Clear $1: 1,3$ & $9,762 \times 10^{-4}$ \\
\hline
\end{tabular}

Dari Tabel 2 di atas dapat diketahui bahwa nilai viskositas dari beberapa bahan. Nilai viskositas dimiliki oleh epoxi yaitu sebesar $31,057 \mathrm{x}$ $\mathrm{Js} / \mathrm{m}^{2}$ sedangkan nilai viskositas terendah oleh clear 1:1,3 yaitu sebesar 9,762 x 10-4 ?erbedaan nilai viskositas disebabkan oleh ngan antara bahan dengan tiner. Pada bahan surfacer, dan clear 1:1 menggunakan ngan 1:1 antara bahan dengan tiner. Clear nggunakan perbandingan 1:1,2 antara bahan iner. Clear 1:1,3 menggunakan perbandingan ara bahan dengan tiner. Pada clear 1:1 - 1:1,3 ni penurunan nilai viskositas seiring a penambahan volume tiner sehingga dapat l bahwa penambahan volume tiner ruh terhadap nilai viskositas.

han PP Primer memiliki nilai viskositas $10,592 \times 10-4 \quad \mathrm{Ns} / \mathrm{m}^{2}$. Bahan ini tidak 1 penambahan tiner karena pada prosedur in PP Primer tidak perlu dilakukan han tiner. Sedangkan bahan epoxi dan menggunakan perbandingan 1:1 antara bahan thinner. Perbandingan ini dipilih karena ngan 1:1 umum digunakan pada pengecatan.

Dari ke 2 bahan tersebut memiliki nilai viskositas yang berbeda yaitu nilai viskositas epoxi sebesar $31,057 \times 10-4 \mathrm{Ns} / \mathrm{m}^{2}$ dan nilai viskositas surfacer sebesar 23,901 x 10-4 Ns/m².

\section{Hasil Pengujian Daya Kilap}

Pengujian daya kilap adalah pengujian yang digunakan untuk menentukan nilai daya kilap dari material yang di uji dengan satuan Gloss Unit (GU). Pengujian daya kilap dilakukan di PT Mataram Paint Surabaya menggunakan alat glossmeter. Hasil pengujian daya kilap dapat dilihat pada Tabel 3.

Tabel 3. Nilai Daya Kilap Temperatur vs Perbandingan Cat dengan Tiner

\begin{tabular}{llllll}
\hline \multirow{2}{*}{ No } & \multirow{5}{l}{ Suhu } & \multicolumn{4}{l}{ Nilai Daya Kilap (GU) } \\
\cline { 3 - 6 } & & \multicolumn{4}{l}{ Perbandingan Volume Cat dan Tiner } \\
\cline { 3 - 6 } & & $1: 1$ & $1: 1,1$ & $1: 1,2$ & $1: 1,3$ \\
1 & $32{ }^{\circ} \mathrm{C}$ & 67,48 & 79,33 & 84,46 & 85,81 \\
2 & $45^{\circ} \mathrm{C}$ & 82,9 & 87,31 & 87,86 & 88,81 \\
3 & $70^{\circ} \mathrm{C}$ & 83,9 & 86,5 & 88,49 & 89,35
\end{tabular}




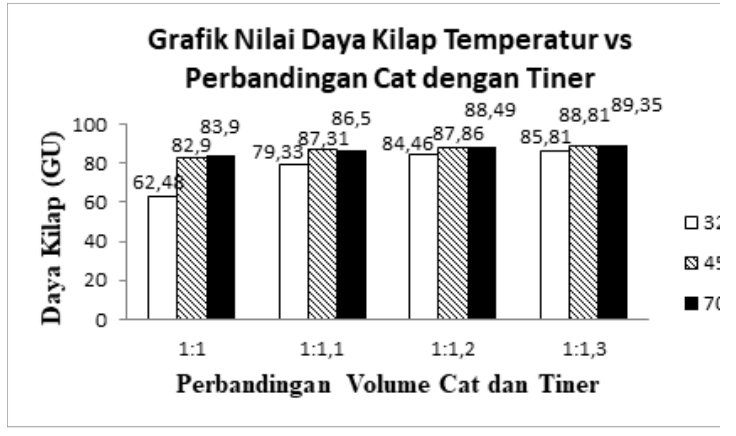

Gambar 2. Grafik nilai rata-rata daya kilap

Dari Tabel 3 dan Gambar 2 dapat dilihat bahwa nilai daya kilap pada masing-masing perbandingan campuran cat dan tiner memiliki hasil yang serupa, yaitu akan naik ketika temperatur pengeringannya naik. Nilai daya kilap terendah terdapat pada suhu 32 ${ }^{\circ} \mathrm{C}$ dan daya kilap tertinggi terdapat pada suhu $70{ }^{\circ} \mathrm{C}$ pada masing-masing perbandingan volume. Nilai tertinggi pada semua variasi terdapat pada perbandingan $1: 1,3$ dengan suhu $70{ }^{\circ} \mathrm{C}$ dengan nilai 89,35 GU, sedangkan nilai terendah pada semua variasi terdapat pada perbandingan 1:1 dengan suhu $32{ }^{\circ} \mathrm{C}$ dengan nilai $62,48 \mathrm{GU}$.

Viskositas atau kekentalan cat yang semakin tinggi mempengaruhi proses atomisasi penyemprotan dimana, campuran cat yang terlalu kental akan menghasilkan permukaan cat yang kurang halus sehingga menyebabkan nilai daya kilap rendah. Hal lain yang mempengaruhi nilai daya kilap adalah pada komponen cat terdapat senyawa nitroselulosa. Nitroselulosa (nitrocellulose) merupakan senyawa polimer dengan kandungan nitrogen sebesar 12,5\%, memiliki daya tahan yang baik terhadap air dan biasa digunakan untuk bahan baku cat yang akan tercampur dengan pigment sehingga menentukan intensitas warna serta reaksi pembentukan film. Pada penelitian Habibie dan Anwar (2014) perbedaan jumlah nitroselulosa menyebabkan tingkat kekentalan cat berbeda dimana semakin banyak kadar nitroselulosa memiliki fungsi bahan dasar serta daya tahan intensitas warna yang lebih baik namun dapat mempengaruhi nilai daya kilap.

\section{Hasil Pengujian Daya Lekat Cat}

Pengujian daya lekat cat merupakan sebuah usaha menentukan kekuatan lapisan cat yang menempel pada medianya dengan metode cross section. Berikut ini adalah hasil pengujian daya lekat cat.

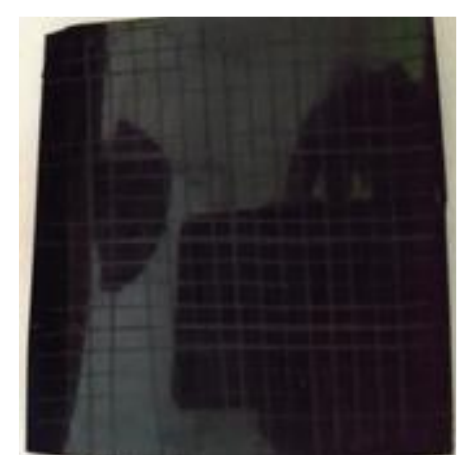

Gambar 3. Cat original bawaan pabrikan

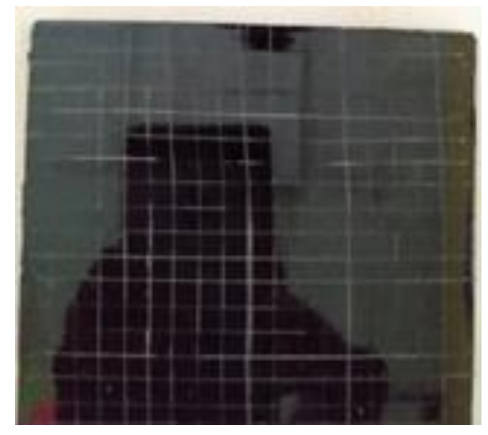

Gambar 4. Hasil pengecatan variasi 1:1,3 $70^{\circ} \mathrm{C}$

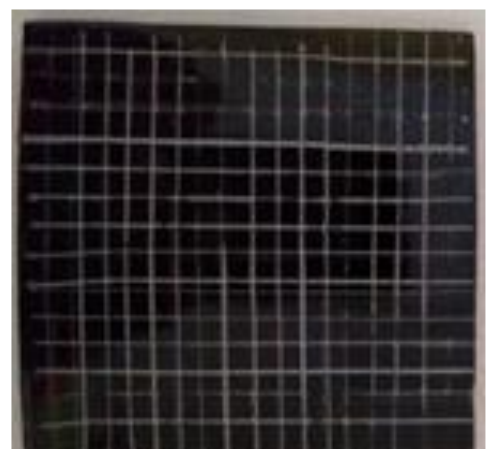

Gambar 5. Hasil pengecatan variasi $1: 132^{\circ} \mathrm{C}$

Berdasarkan hasil pengujian daya lekat cat menghasilkan penampakan visual yang baik pada semua spesimen. Hal ini dikarenakan pada saat pengujian daya lekat cat tidak ada cat yang terkelupas sehingga semua spesimen termasuk dalam kelas 5 B ASTM D3359. Penyebab tidak ada cat yang terkelupas di pengaruhi beberapa faktor yaitu: pada lapisan terakhir (finishing) terdapat clear yang 
berfungsi memberi daya kilap pada top coat serta melindungi top coat agar lebih kuat dan warna pada top coat tidak cepat memudar, serta teknik pengecatan yang baik. Serta saat penyemprotan cat masih manual yang menyebabkan jarak saat melakukan penyemprotan bisa berubah sehingga menyebabkan ketebalan cat yang berbeda.

\section{PENUTUP}

\section{Kesimpulan}

Berdasarkan penelitian yang dilakukan dan pembahasan dapat diambil beberapa kesimpulan sebagai berikut:

1. Hasil pengujian daya lekat cat rata-rata semua semua komponen memiliki daya lekat yang baik dan termasuk dalam kelas 5B, Hasil pengujian nilai daya kilap terendah sebesar 67,48 GU terdapat pada temperatur $32{ }^{\circ} \mathrm{C}$ dengan perbandingan antara volume cat dan tiner 1:1, sedangkan nilai daya kilap tertinggi sebesar 89,35 GU terdapat pada suhu $70{ }^{\circ} \mathrm{C}$ dengan perbandingan antara volume cat dan tiner 1:1,3.

2. Viskositas cat semakin tinggi menyebabkan kadar nitroselulosa dalam cat semakin tinggi sehingga menyebabkan nilai daya kilap semakin rendah namun daya tahan cat terhadap goresan meningkat. Sebaliknya viskositas cat semakin rendah menyebabkan kadar nitroselulosa dalam cat semakin rendah menyebabkan nilai daya kilap semakin tinggi, namun daya tahan cat terhadap goresan menurun.

\section{Saran}

Dari penelitian yang telah dilakukan, maka saran untuk penelitian selanjutnya adalah sebagai berikut:

1. Menggunakan tiner high gloss untuk mengetahui perbedaan nilai daya kilap dan daya lekat.

2. Waktu pengeringan cat bisa diperlama dari 1 jam bisa menjadi 2 atau 3 jam.

3. Membuat alat pengatur jarak pengecatan agar hasilnya lebih baik karena jika menggunakan tangan bisa terjadi perbedaan jarak pengecatan yang menyebabkan ketebalan cat berbeda.

4. Dalam penelitian ini ditemukan perbedaan kedalaman goresan ketika dilakukan pengujian daya lekat cat. Sehingga dalam penelitian selanjutnya dapat digunakan sebagai dasar untuk pengujian ketebalan cat.

\section{DAFTAR PUSTAKA}

[1] ASTM International. 2017. ASTM D3359-17 Standard Test Methods for Rating Adhesion by Tape Test. West Conshohocken, PA. www.astm.org

[2] Gunadi. 2008. Teknik Bodi Otomotif Jilid 3. Jakarta: Pusat Perbukuuan Departemen Pendidikan Nasional

[3] Habibie, Johansyah N., Anwar S. 2014. Pengaruh Campuran Cat Dengan Thinner Terhadap Kualitas Hasil Pengecatan. Skripsi. Jurusan Teknik Mesin. Fakultas Teknik. Universitas Negeri Surabaya

[4] Irawan, D. A. dan Wulandari, Dian. 2016. Pengaruh Jarak Penyemprotan Spray Gun dan Perbandingan Campuran Cat Dengan Thinner Terhadap Kualitas Hasil Pengecatan. Skripsi. S1 Pendidikan Teknik Mesin. Fakultas Teknik. Universitas Negeri Surabaya

[5] ISO 2409:2007. 2019. Paints And Varnish Cross Cut Test. BS EN ISO 2409:2007

[6] Khasib, A. dan Wulandari, D. 2017. Pengaruh Variasi Penggunaan Thinner Pada Campuran Cat Terhadap Kualitas Hasil Pengecatan. JPTM Vol 06 No. 01. Fakultas Teknik Universitas Negeri Surabaya.

[7] Permana, F. I. dan Anwar, S. 2014. Pengaruh Kualitas Thinner Pada Campuran Cat Terhadap Hasil Pengecatan. Skripsi. S1 Pendidikan Teknik Mesin Otomotif, Fakultas Teknik, Universitas Negeri Surabaya

[8] PT Toyota Astra Motor. 2011. New Step 1 Training Manual. Jakarta: PT Toyota Astra Motor Training Center

[9] Tita. 2019. Prinsip Kerja Viskometer Oswaldt. http://www.scribd.com/document/327736515. [03 Februari 2019] 